\title{
FOUCAULT, PARA ALÉM DO PODER DISCIPLINAR E DO BIOPODER*
}

\author{
THAMY POGREBINSCHI
}

Michel Foucault jamais dedicou um livro ao tema do poder. No entanto, é possível afirmar que esse é um assunto que se espraia ao longo de toda a sua obra, sob as mais variadas formas. Seja no contexto das sólidas análises históricas que empreendeu, seja na voz desafiadora que tantas vezes levantou cumprindo aquilo que acreditava ser o verdadeiro papel de um intelectual, Foucault permanentemente encontrava-se concernido com a problemática do poder. Uma teoria geral sobre o poder, no entanto, nunca foi gerada, mas também nunca foi ambicionada. ${ }^{1}$ Todavia, ao debruçar-se sobre as questões da loucura ou da sexualidade, sobre as prisões ou os asilos, Foucault jamais deixou de preocupar-se com o poder. Por esse motivo, a questão do poder é indissociável de sua obra e constitui-se em um tema imanente ao seu pensamento. Devido ao seu caráter fragmentário e a sua condição esparsa no conjunto da obra, o conceito de poder foucaultiano foi

\footnotetext{
* Gostaria de agradecer ao parecerista anônimo da revista Lua Nova pelas imprescindíveis e valiosas contribuições à versão final deste artigo.

1 Testemunho disso são as palavras com que Foucault inicia o artigo "O Sujeito e o Poder", publicado por Rabinow e Dreyfus em 1983: "As idéias que eu gostaria de discutir aqui não representam nem uma teoria nem uma metodologia. Eu gostaria de dizer, antes de mais nada, qual foi o objetivo do meu trabalho nos últimos vinte anos. Não foi analisar o fenômeno do poder nem elaborar os fundamentos de tal análise. Meu objetivo, ao contrário, foi criar uma história dos diferentes modos pelos quais, em nossa cultura, os seres humanos tornaram-se sujeitos. (...) Assim, não é o poder, mas o sujeito, que constitui o tema geral de minha pesquisa. É verdade que me envolvi bastante com a questão do poder (...). Era necessário estender as dimensões de uma definição de poder se quiséssemos usá-la ao estudar a objetivação do sujeito. Será preciso uma teoria do poder? Uma vez que uma teoria assume uma objetivação prévia, ela não pode ser afirmada como uma base para um trabalho analítico. Porém, este trabalho analítico não pode proceder sem uma conceituação dos problemas tratados, conceituação esta que implica um pensamento crítico - uma verificação constante". Cf. Foucault 1995a: 231-232."
} 
muitas vezes objeto de mal-entendidos, equívocos ou falsas interpretações. ${ }^{2}$ Além da ausência de sistematicidade e de linearidade, um outro motivo que talvez explique essa suposta inocorrência de univocidade ou mesmo de veracidade nas interpretações que o tema suscitou é a presença constante e concomitante das categorias do poder disciplinar e do biopoder na obra fou-

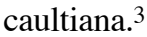

São dois os problemas gerados por esse fato. O primeiro diz respeito a um equívoco em torno desses dois conceitos de poder. Sobre isso comentam Fontana e Bertani: "Esses dois poderes não constituíram, pois, como se disse às vezes, duas 'teorias' no pensamento de Foucault, uma exclusiva da outra, uma independente da outra, uma sucessiva à outra, mas, antes, dois modos conjuntos de funcionamento do saber/poder, tendo, é verdade, focos, pontos de aplicação, finalidades e móbeis específicos" (Fontana e Bertani 1999: 330). Já o segundo problema se refere a um equívoco relativo ao conteúdo próprio e específico do conceito foucaultiano de poder, que não se confunde nem com o poder disciplinar, nem com o biopoder. É sobre este segundo problema que queremos nos debruçar neste pequeno artigo.

Nossa hipótese é a de que o conceito de poder cunhado por Foucault encontra-se além daquilo que as suas investigações históricas conferiram ao poder disciplinar e ao biopoder. Um núcleo comum entre essas

${ }^{2}$ Esta é também a opinião de Alessandro Fontana e Mauro Bertani, professores autorizados pela Associação para o Centro Michel Foucault (dirigido por Fontana e François Ewald) para editar e publicar os cursos ministrados por Foucault no Collège de France. Cf. Fontana e Bertani 1999: 330.

3 Como se sabe, Foucault também dissertou sobre o poder pastoral, sobre o poder como guerra e como governamentalidade, mas essas categorias jamais alcançaram o mesmo status e dimensão que o poder disciplinar e o biopoder na primeira fase de sua obra. É por esse motivo elas não serão consideradas neste artigo. Também nos eximiremos de analisar a idéia de resistência, mesmo sabendo que, ao contrário daquelas categorias acima mencionadas, possui um papel central no tratamento que o tema do poder recebe em sua obra como um todo. Apesar disso, a despeito de sua presença contínua no corpo da obra, acreditamos que é uma noção mais central na sua segunda fase, a qual optamos por não analisar neste artigo em coerência ao seu escopo de focar nos conceitos de poder disciplinar e biopoder a fim de utilizá-los como o contraponto que nos permitirá identificar o núcleo emancipatório do conceito foucaultiano de poder que constitui o fulcro principal deste artigo.

${ }^{4}$ Não estamos postulando aqui, evidentemente, a existência de um outro conceito de poder que, pela diferenciação, cancele os demais. Ao contrário, reconhecemos que existe não apenas um, mas alguns conceitos de poder em Foucault, que variam, por exemplo, de acordo com o ângulo de análise, o contexto de seu enunciado e a época de sua formulação. O que estamos querendo identificar aqui, portanto, é um conteúdo (um núcleo) do conceito de poder foucaultiano que não se confunde com as categorias do poder disciplinar e do biopoder e se define justamente como contraponto delas. 
duas categorias e um outro conceito de poder, abstrato, inominado, existe, entretanto, e é o que permite identificá-lo. ${ }^{4}$ Trata-se de um núcleo teóricoconceitual que, ao afastar o poder da idéia de repressão e de lei, o torna emancipatório, libertador. Trata-se, afinal, de um conceito de poder como produtividade, como positividade. A chave para encontrar esse núcleo comum nos conceitos de poder disciplinar e de biopoder é a permanência em ambos do poder-saber, da idéia de poder enquanto produtor de conhecimento. Mas não é só isso. O que há de propositivo e não de meramente descritivo naquilo que Foucault escreve sobre o poder, o que há além daquelas duas categorias que se tornaram tão conhecidas e tão comentadas, o que há nesse conceito de poder abstrato e inominado que Foucault deixa entrever em vários momentos, potencializa a idéia de produtividade e de positividade até torná-la emancipadora, até convertê-la em emancipação.

Para tentar alcançar nosso objetivo de encontrar esse núcleo inominado do poder em Foucault - para tentar encontrar, enfim, um significado do conceito de poder foucaultiano que não é nem o poder disciplinar nem o biopoder - adotaremos como estratégia metodológica, neste artigo, uma análise concentrada no primeiro período (ou fase genealógica) da obra de Foucault, deixando para outra ocasião uma análise mais detida do segundo e último período, que abrange seus textos finais (a hermenêutica do sujeito). Tal opção metodológica se justifica porque é justamente na primeira fase de sua obra que Foucault desenvolve prioritariamente os conceitos de poder disciplinar e biopoder, os quais elegemos aqui como contraponto crítico desse núcleo emancipatório que tencionamos identificar no conceito foucaultiano de poder. 5

\section{NOTAS METODOLÓGICAS (E GENEALÓGICAS)}

É preciso identificar, antes de qualquer outra coisa, o modo pelo qual a questão do poder surge para Foucault como um problema

\footnotetext{
${ }^{5}$ Nossa estratégia analítica aqui, portanto, é a de mostrar como essa concepção se define pela negativa no primeiro momento da obra de Foucault. Já nos seus últimos escritos, essa mesma concepção se definiria a partir de outra estratégia metodológica de análise, estratégia essa que não exigiria o contraponto conceitual nem a definição pela negação, mas sim uma aproximação e positivação, dada a afirmação de seu estatuto imanente em outros conceitos, como aquele do 'cuidado de si', que deveriam, então, ocupar o lugar central que o poder disciplinar e o biopoder desempenham neste artigo.
} 
metodológico. O que aqui se deve aventar primeiramente é o fato de que Foucault se cerca de certas precauções metodológicas ao tecer a sua análise genealógica do poder. Em primeiro lugar, a primeira dessas precauções, talvez possamos denominar como princípio da localidade. O poder é analisado por Foucault em suas formas e em suas instituições mais locais. Ao afastar sua genealogia de um suposto centro do poder, ao optar pela exegese de mecanismos específicos e não daqueles gerais, Foucault também faz uma opção metodológica em prol do afastamento de uma compreensão juridicizada do poder. Seu desejo é o de ir para além das regras de direito que organizam e delimitam o poder: é atrás delas que estão as técnicas, os instrumentos e até mesmo as instituições que Foucault quer trabalhar. É nesse contexto que, por exemplo, o poder de punir se consolida no suplício: trata-se de um olhar voltado para extremidades, com a ressalva de que essas extremidades se situem para além do jurídico. ${ }^{6}$

O segundo cuidado da ordem do método chamaremos de princípio da exterioridade ou da objetivação. Trata-se, nas palavras de Foucault, "de não analisar o poder no nível da intenção ou da decisão", mas sim de estudá-lo sob a perspectiva de sua externalidade, no plano do contato que estabelece com o seu objeto, com o seu campo de aplicação. Trata-se, afinal, de buscar o poder naquele exato ponto no qual ele se estabelece e produz efeitos (Foucault 1999: 33). É aqui que podemos identificar talvez o incessante desejo de objetivação, o 'objetivismo irremediável' sobre qual fala Habermas ao desbravar a obra de Foucault (Habermas 2002: 387).

A terceira preocupação metodológica denominaremos como princípio da circularidade ou transitoriedade, tendo em vista que consiste na idéia de que o poder se exerce em uma espécie de rede na qual os indivíduos estão, a cada momento, seja em posição de exercer o poder, seja em posição de serem submetidos a ele. Em outras palavras, o poder é algo que circula incessantemente sem se deter exclusivamente nas mãos de ninguém: potencialmente, todos são, ao mesmo tempo, detentores e destinatários do poder, seus sujeitos ativos e passivos - se é que podemos falar em sujeito aqui. Como diz Foucault, "o poder transita pelos indivíduos, não se aplica a eles (...) o poder transita pelo indivíduo que ele constituiu" (Foucault 1999: 35).

Em quarto lugar, Foucault orienta-se metodologicamente por aquilo que chamaremos de princípio da ascensão. Em sua empreitada de

${ }^{6}$ Mais adiante, neste artigo, outros argumentos tornarão clara essa recusa metodológica de Foucault em relação a uma abordagem jurídica do poder. 
romper com a visão jurídica do poder cunhada pela filosofia política moderna, Foucault rejeita uma análise descendente, isto é, que parta de cima, do alto (do soberano, por exemplo) para baixo. Ao contrário, a trajetória que Foucault quer fazer parte de baixo para cima. Essa é a genealogia foucaultiana: uma análise ascendente do poder, que parte de seus mecanismos moleculares, infinitesimais, até chegar àqueles gerais, globais. Não é de se surpreender que, na contramão da produção teórica contemporânea - como a de Habermas e Rawls, por exemplo -, Foucault não busca compreender o poder pela via das instituições estatais, mas sim através de pequenas técnicas, procedimentos, fenômenos e mecanismos que constituem efeitos específicos - e não gerais ou globais - de poder.

Finalmente, a última das orientações metodológicas de que se cerca Foucault em sua análise do poder nos parece poder ser designada na forma de um princípio da não-ideologização. Foucault quer afastar-se das compreensões ideológicas do poder e substituir, no lugar das ideologias, os saberes. O que está na base do poder, diz Foucault, não são as ideologias, mas instrumentos de formação e acúmulo de saber. Ao exercer-se, o poder forma, organiza e coloca em circulação um dispositivo de saber.

O ponto de partida de Foucault ao analisar o tema do poder, portanto, parece ser o desejo de rompimento com aquilo que ele chama de teorias jurídicas do poder. Com efeito, trata-se de romper com todo o arsenal teórico produzido desde a filosofia política moderna no sentido de justificar o poder através do contratualismo. Quando Foucault afirma que é preciso estudar o poder fora do modelo do Leviatã, o que ele quer ressaltar é a necessidade de se pensar o poder fora do campo do Estado e, mais especificamente, da soberania e de suas instituições. Mas isso também não significa que o poder deve ser pensado em termos marxistas. A noção de dominação também não é suficiente para dar conta do conceito de poder, diz Foucault; não se a ela não for concedida uma conotação eminentemente positiva - coisa que o marxismo, segundo ele, não fez.

O problema das concepções jurídicas ou marxistas do poder é aquele que Foucault chama de 'economicismo na teoria do poder': "Me parece que existe um ponto em comum entre a concepção jurídica ou liberal do poder político e a concepção marxista, ou uma certa concepção corrente que passa como sendo a concepção marxista" (Foucault 1979: 174). A análise econômica posta em prática pela teoria jurídica clássica consiste em associar o poder a um direito, que pode ser possuído e, por consequiência, transacionado. Em outras palavras, o poder seria algo passível de ser transferido ou alienado, como um bem qualquer. É aqui que entra a figura 
do contrato, instrumento jurídico por excelência, para operar esse tipo de transação com o poder - como se dá, por exemplo, na constituição do poder político (da soberania), quando os indivíduos supostamente cedem seu poder ao soberano por meio de um pacto. Já no caso da concepção marxista do poder, a análise economicista do conceito de poder é empreendida de outra forma, ressaltando-se a 'funcionalidade econômica do poder': aqui, o poder teria basicamente o papel de manter as relações de produção e reproduzir a dominação de classe operada pelo capitalismo. Sobre a forma pela qual essas duas abordagens realizam uma análise economicista do poder, diz Foucault: "em um caso temos um poder político que encontraria no procedimento de troca, na economia da circulação dos bens o seu modelo formal e, no outro, o poder político teria na economia sua razão de ser histórica, o princípio de sua forma concreta e do seu funcionamento atual" (Foucault 1979: 175).

Qual é então a alternativa, se o que se quer é evitar uma análise econômica do poder? As respostas existentes - que também não são suficientes para Foucault - consistem em subsumir o poder à idéia de ação ou de força. É daqui que se originam as concepções repressivas do poder, ou melhor, as interpretações do poder como repressão. Se encarar o poder como ação o leva a ser compreendido sob o enfoque da repressão, encarálo como força o faz ser analisado em termos de combate, de confronto, enfim, de guerra.

$$
\begin{aligned}
& \text { Poder }=\text { Ação }=\text { Repressão } \\
& \text { Poder }=\text { Força }=\text { Guerra }
\end{aligned}
$$

As alternativas disponíveis quando são evitadas as abordagens economicistas são, portanto, duas. A primeira, que identifica poder com repressão, Foucault chama de 'hipótese de Reich'. Quanto à segunda, que associa poder e força e, por conseguinte, poder e guerra, Foucault denomina como 'hipótese de Nietzsche' (Foucault 1979: 176). Essas duas hipóteses são articuladas por Foucault, de forma a consolidar dois esquemas de análise do poder aos quais ele deseja se opor: a abordagem jurídica ou do 'contrato-opressão', e a abordagem marxista ou da 'guerra-repressão'.

Portanto, o conceito de poder de Foucault tem a ambição de, a um só tempo, romper com os esquemas predominantes de interpretação seja aquilo que ele chama economicismo na teoria do poder, no caso das abordagens jurídicas e marxistas, sejam aquelas concepções outras que privilegiam o conteúdo belicoso ou repressivo do poder. Além disso, outro 
importante pressuposto que informa amplamente todo o ponto de partida de Foucault em suas investigações sobre o poder é, como já foi dito acima, a necessidade de encontrá-lo fora do âmbito do Estado e de suas instituições. Pressuposto esse que, é claro, vem também ao encontro do desejo de Foucault de romper com as concepções jurídicas do poder que o levam a ser identificado com o conceito de soberania. O conceito de poder foucaultiano vai ser formulado a partir de um olhar que perpassa o Estado, que vai além dele, para buscar no micro e não no macro os elementos moleculares de sua realização cotidiana.

O conceito de poder foucaultiano se situa, entretanto, em algum lugar entre o direito e a verdade. Foucault quer estudar o modo pelo qual o poder se exerce, o "como do poder", conforme ele mesmo explica - em outras palavras, isso equivale a compreender os mecanismos do poder balizados entre os limites impostos de um lado pelo direito, com suas regras formais delimitadoras, e de outro pela verdade, cujos efeitos produzem, conduzem e reconduzem novamente ao poder. É nesse sentido que Foucault menciona a relação triangular que se estabelece entre esses três conceitos: poder, direito e verdade (Foucault 1999: 28).

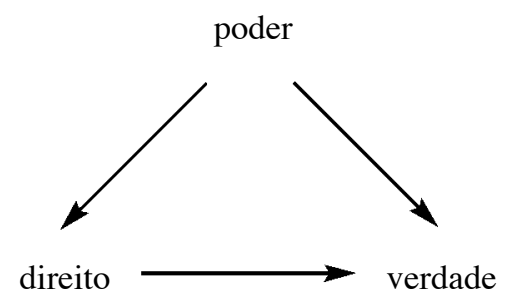

Quais são as regras de direito de que se valem as relações de poder para produzir discursos de verdade? É essa a principal questão que Foucault parece querer responder na primeira metade da década de 1970, em suas pesquisas no Collège de France preliminares à publicação de Vigiar e punir. A produção da verdade, aliás, sabe-se que é um tema constante em Foucault, seja sob a ótica do poder, seja sob a ótica da sexualidade ou da loucura, por exemplo. O se passa entre esses dois conceitos, o de poder e o de verdade, só pode ser entendido sob uma perspectiva relacional: "somos submetidos pelo poder à produção da verdade e só podemos exercer o poder mediante a produção da verdade" (Foucault 1999: 28). Como bem observa Habermas, o que se passa é que Foucault torna a verdade dependente do poder - invertendo uma relação que, no âmbito da 
filosofia do sujeito, supostamente se exerceria no sentido contrário (Habermas 2002: 385). ${ }^{7}$

$\mathrm{O}$ poder, portanto, institucionaliza a verdade. Ou, ao menos, ele institucionaliza abusca da verdade ao institucionalizar seus mecanismos de confissão e inquirição. A verdade se profissionaliza, pois, afinal, no seio daquela relação triangular, a verdade é a norma: nesse sentido, e antes de mais nada, são os discursos verdadeiros que julgam, condenam, classificam, obrigam, coagem... trazendo sempre consigo efeitos específicos de poder.

\section{A POSITIVIDADE E A PRODUTIVIDADE DO PODER}

Para compreender a dimensão produtiva e positiva do conceito de poder foucaultiano é necessário entender antes sua ambição de rejeitar aquilo que chama de 'hipótese repressiva' do poder e, por conseguinte, a relação que os conceitos de poder e saber usufruem em seu sistema de pensamento. No primeiro volume de seu História da sexualidade, Foucault se indaga acerca das supostas relações existentes entre o dispositivo da sexualidade e a mecânica do poder. Em outras palavras, o objetivo de Foucault nesse livro é o de, simultaneamente, verificar se a repressão do sexo constitui de fato uma evidência histórica e se as relações de poder são de fato de ordem repressiva. Para ambas as questões que se coloca, a resposta de Foucault, como se sabe, é negativa. Disso decorre que o escopo central dessa obra parece ser o de afastar a 'hipótese repressiva', seja no que tange ao dispositivo da sexualidade, seja no que concerne à mecânica do poder.

Afastar a hipótese repressiva significa, antes de qualquer coisa, substituir o que seria uma 'teoria' do poder por uma 'analítica' do poder. Uma analítica do poder - que define o domínio específico formado pelas relações de poder, bem como os instrumentos que permitem analisá-lo - só é possível, por sua vez, se expurgada for aquilo que Foucault chama nesse livro de "concepção jurídico-discursiva" do poder, ou seja, mais uma vez, as teorias jurídicas constitutivas da imagem do poder enquanto soberania estatal. Tal concepção seria responsável por promover as associações, predominantes nas análises políticas, entre poder e repressão, poder e lei, poder e interdição e poder e censura (Foucault 2001a: 80 e segs). Foucault

7 Bastante ilustrativo dessa afirmação é o texto de Foucault intitulado "Verdade e Poder". Cf. Foucault 1979: 01-14. 
vai, portanto, buscar na História a falsidade de tais associações, de modo a refutar a teoria que as sustentam.

"No pensamento e na análise política ainda não cortaram a cabeça do rei" (Foucault 2001a: 86). Com essa bela frase Foucault exprime o que pode ser a síntese daquilo que rejeita nas teorias jurídicas do poder: uma permanência além do tempo, além da História, da representação monárquica do poder, dos problemas então suscitados pelo direito e pela violência, enfim, pela encarnação do poder na figura do soberano e, mais contemporaneamente, na figura do Estado enquanto ser coletivo. Essa visão jurídica do poder, ao pretender as associações acima mencionadas, responde pela conotação negativa que o poder assumiu historicamente na formulação do pensamento ocidental. E para que o poder deixe de ser visto como algo negativo, para que deixe de ser associado com repressão e interdição, é preciso que ele deixe de ser visto como lei, como direito... é preciso enfim, que se rompa com essa sua visão jurídica, que se corte a cabeça do rei!

É essa a limpeza de terreno que Foucault parece considerar necessária para que uma analítica do poder possa ser colocada em prática. Foucault de fato acreditava que, como procurara demonstrar em Vigiar $e$ punir, há séculos já havia sido instaurado um tipo de sociedade na qual o jurídico passou a perder progressivamente a sua capacidade de codificar e representar o poder. Alterando-se, portanto, a chave de interpretação histórica, olhando as sociedades modernas mais de perto, percebe-se que o direito cede lugar à técnica, bem como a lei à normalização. Nesse contexto, o poder transparece antes em seu aspecto positivo e produtivo; ele se encontra na verdade irrompendo em pequenos mecanismos, técnicas e procedimentos e, mais do que isso: o poder se encontra em mecanismos positivos, produtores de saber, multiplicadores de discursos, indutores de prazer e geradores de mais poder.

Essa virada metodológica no que concerne à compreensão do conceito de poder vai permitir que Foucault no primeiro volume da História da sexualidade passe a analisar a formação de um certo tipo de saber sobre o sexo, não em termos de repressão ou de lei, mas em termos de poder. Nesse momento, Foucault passa a formular o conceito de poder em sua forma mais abstrata possível, sem encaixá-lo no contexto de suas análises históricas e, por conseguinte, sem enquadrá-lo em categorias como as de poder soberano, poder disciplinar ou biopoder - as quais analisaremos detidamente adiante. Em sua forma, portanto, mais abstrata, o conceito foucaultiano de poder não mantém nenhum contato com os conceitos de Estado, soberania, lei e dominação. Ele é sim compreendido como 
a multiplicidade de correlações de força imanentes ao domínio onde se exercem e constitutivas de sua organização; o jogo que, através de lutas e afrontamentos incessantes as transforma, reforça, inverte; os apoios que tais correlações de força encontram umas nas outras, formando cadeias ou sistemas ou, ao contrário, as defasagens e contradições que as isolam entre si; enfim, as estratégias em que se originam e cujo esboço geral ou cristalização institucional toma corpo nos aparelhos estatais, na formulação da lei, nas hegemonias sociais. (Foucault 2001a: 89)

Compreendida em sua dinâmica e movimento intencionais, a formulação desse conceito deixa clara como o Estado e a lei surgem apenas naquilo que Foucault chama de 'forma terminal' do poder. Seja esboço ou cristalização, o fato é que não se encontram onde o poder se encontra, onde ele se inicia e floresce, mas apenas onde ele cessa de ser poder. Ora, se o poder consiste em relações de força, múltiplas e móveis, desiguais e instáveis, é evidente que ele não pode emanar de um ponto central, mas sim de instâncias periféricas, localizadas. Ao lado da impossibilidade da centralidade, está a impossibilidade da unidade. O poder está, ao mesmo tempo, em todos os pontos do suporte móvel das correlações de força que o constitui; está em toda parte, na relação de um ponto com outro, enfim multiplica-se e provém, simultaneamente, de todos os lugares.

Quando ao poder é conferido o seu real significado, sendo-lhe removidos os anacrônicos atributos que as teorias jurídicas insistiram e persistiram em lhe conferir, nesse momento então se torna possível realizar a tarefa inicial da História da sexualidade, qual seja, indagar acerca das relações entre a mecânica do poder e o dispositivo da sexualidade. É nesse contexto, afinal, que Foucault quer analisar a emergência dos discursos sobre o sexo no campo das relações de poder e é aqui que se encontra também a relação de imanência existente entre os conceitos de poder e saber: "entre técnicas de saber e estratégias de poder, nenhuma exterioridade; mesmo que cada uma tenha seu papel específico e que se articulem entre si a partir de suas diferenças. Partir-se-á, portanto, do que se poderia chamar de focos locais de poder-saber" (Foucault 2001a: 93-94). Poder e saber - poder-saber, portanto, esse outro conceito foucaultiano que é ao mesmo tempo duplo e singular, plural e único - se articulam, por conseguinte, justamente no seio dos discursos sobre o sexo. São estes discursos, e não outros, que Foucault elege para demonstrar como as estratégias de poder são imanentes à vontade de saber. E por quê? O que mais o poder e o sexo 
tem em comum além de terem sido por tanto tempo mal-compreendidos sob o estigma da repressão?

Portanto, retornamos ao nosso ponto de partida e percebemos como são vários os fatores passíveis de explicar a incompatibilidade existente entre o conceito foucaultiano de poder e a idéia de repressão. Como vimos, a produtividade do poder afasta a hipótese repressiva: a noção de produtividade, imanente ao conceito de poder foucaultiano, torna a noção de repressão algo inadequado. Além do que, a idéia de repressão implica diretamente em uma percepção negativa do poder; fato esse que Foucault, como já sabemos, quer a todo custo evitar. Acrescente-se a isso o fato de que a idéia de repressão também se associa a uma abordagem jurídica do poder. Como sabemos, quando encarado pelo ângulo da repressão, o poder é compreendido como uma norma e, mais do que isso, como uma norma proibitiva, ou seja, que diz não - o que só viria, por sua vez, reforçar o caráter negativo do poder que Foucault quer justamente evitar. ${ }^{8}$

A hipótese repressiva precisa ser afastada, portanto, para imprimir no poder um aspecto positivo. Aqui está então essa tão importante característica do conceito de poder foucaultiano: a positividade. "Temos que deixar de descrever sempre os efeitos de poder em termos negativos", proclama definitivamente Foucault (Foucault 2001b: 161). Ao lado da positividade, outra característica do poder é a imaterialidade. O poder está, ao mesmo tempo, em toda parte e em lugar nenhum. Ele é, a um só tempo, visível e invisível, presente e oculto. O fato é que o poder não pode ser apropriado; não por uma mesma classe, não de forma exclusiva, não de forma permanente, não por um mesmo grupo de pessoas: "o poder não é algo que se adquira, arrebate ou compartilhe, algo que se guarde ou deixe escapar" (Foucault 2001a: 89). Além disso, o poder é também imanente, isso é, ele não se encontra em uma posição de exterioridade em relação a coisas outras tais como o saber e o sexo, por exemplo. Ao contrário, o poder pode constituir os efeitos imediatos e as condições internas desses outros processos ou relações com os quais ele se liga. O poder é ainda não-subjetivo, vale dizer, ele não é passível de titularidade: todos o possuem, ao mesmo tempo em que ninguém o detém: “onde há poder ele se exerce (...) não se sabe ao certo quem o detém; mas

8 Sobre a passagem de uma concepção negativa a uma concepção positiva da norma, veja Macherey 1989. 
se sabe quem não o possui” (Foucault 1979: 75). Pode-se ainda, por fim, dizer que o poder é não-dualístico, pois que não se apóia em oposições binárias do tipo dominadores versus dominados, entre outras. Mais uma vez, o que vem a corroborar essa característica é o aspecto plural... múltiplo, multifocal, multiforme e multifário que o poder assume na analítica e não na teoria - de Foucault.

O sexo sem a lei e o poder sem o rei. É essa, afinal, a idéia principal que Foucault parece querer imprimir no primeiro volume de seu História da sexualidade. Trata-se de uma espécie de limpeza de terreno que talvez faça sentido quando lembramos a proximidade temporal entre a publicação dessa obra (1976) e de Vigiar e punir (1975). O que estava, portanto, entre os objetivos desse segundo livro era mostrar como que a partir dos séculos XVII a XVIII houve uma espécie de desbloqueio tecnológico da produtividade do poder (Foucault 1979: 08). E como, além disso, naquele momento, já era possível deixar de se falar em poder da soberania para se falar em poder disciplinar.

\section{DO PODER DISCIPLINAR AO BIOPODER}

Ao longo dos séculos XVII e XVIII, portanto, no que tange às relações de poder, muitas transformações passam a ser operadas. A mais importante delas consiste certamente na constatação foucaultiana de que $o$ poder da soberania é substituído gradativamente pelo poder disciplinar e, por conseguinte, as monarquias soberanas se convertem aos poucos em verdadeiras sociedades disciplinares. Mas a que se deve esta transformação histórica? É nesse ponto que a pesquisa de Foucault revela que, ao longo desses dois séculos, multiplicaram-se por todo o corpo social verdadeiras instituições de disciplina, tais como as oficinas, as fábricas, as escolas e as prisões - que passam a constituir seu objeto de investigação em Vigiar e punir.

Ao contrário do que ocorre no âmbito do poder da soberania, o poder disciplinar não se materializa na pessoa do rei, mas nos corpos dos sujeitos individualizados por suas técnicas disciplinares. Enquanto que o poder da soberania, ou poder soberano, se apropria e expia os bens e riquezas dos súditos, o poder disciplinar não se detém como uma coisa, não se transfere como uma propriedade: "o poder disciplinar é com efeito um poder que, em vez de se apropriar e retirar, tem como função maior ades trar; ou sem dúvida adestrar para retirar e se apropriar ainda mais e 
melhor" (Foucault 2001b: 143). Isso porque a modalidade disciplinar do poder faz aumentar a utilidade dos indivíduos, faz crescer suas habilidades e aptidões e, conseqüentemente, seus rendimentos e lucros. O poder disciplinar, através de suas tecnologias de poder específicas, torna mais fortes todas as forças sociais, uma vez que leva ao aumento da produção, ao desenvolvimento da economia, à distribuição do ensino e à elevação da moral pública, por exemplo (Foucault 2001b: 172).

$\mathrm{Na}$ medida em que a base da sociedade passa a se ver de ponta a ponta atravessada por mecanismos de disciplina, invertem-se também os princípios da centralidade e da visibilidade do poder. Vejamos como. Enquanto que, no caso do poder da soberania, o poder encarnava-se na figura do soberano e esse se encontrava, justamente por isso, no centro das relações de poder, já na hipótese do poder disciplinar, não há um centro único de poder e nem mesmo uma figura única que o encarna: o poder encontra-se nas periferias, distribuído e multiplicado em toda parte ao mesmo tempo, materializado que está nos corpos dos indivíduos a ele sujeitados. Além disso, observe-se que, no caso do poder disciplinar, o poder se exerce por meio de uma extensa e ameaçadora visibilidade da pessoa do soberano, a quem todos devem conhecer e reconhecer posto que é a sua autoridade que centraliza os efeitos do poder. Ao contrário, no caso do poder disciplinar, essa relação se inverte. Conforme veremos mais detidamente logo a seguir, o poder disciplinar deve manter-se na invisibilidade para funcionar, pois que a sua invisibilidade ressalta a visibilidade daqueles que a ele se sujeitam, de modo que a sua eficácia é constante e permanente. Mas vamos com calma até chegar lá.

Além da multiplicação das instituições de disciplina, Foucault observou que os séculos XVII e XVIII também assistiram a uma efusão de dispositivos disciplinares ao longo de toda a extensão da estrutura da sociedade. Mas em que consistem esses dispositivos disciplinares? Em que consiste, afinal, a disciplina? A disciplina é uma tecnologia específica do poder, ela é "um tipo de poder, uma modalidade para exercê-lo, que comporta todo um conjunto de instrumentos, de técnicas, de procedimentos, de níveis de aplicação, de alvos; ela é uma física ou uma anatomia do poder, uma tecnologia" (Foucault 2001b: 177). Na medida em que o poder disciplinar é uma modalidade de poder múltipla, relacional, automática e anônima, a disciplina, por sua vez, também faz crescer e multiplicar aquilo e aqueles que estão a ela submetidos. Nesse sentido, pode-se dizer que a disciplina é uma técnica que fabrica indivíduos úteis. A disciplina faz crescer e aumentar tudo, 
sobretudo a produtividade. E aqui se fala em produção não apenas em um sentido econômico. Além de ampliar a produtividade dos operários nas fábricas e oficinas, a disciplina faz aumentar a produção de saber e de aptidões nas escolas, de saúde nos hospitais e de força no exército, por exemplo. São por esses motivos, principalmente, que Foucault fala em um triplo objetivo da disciplina: ela visa tornar o exercício do poder menos custoso - seja econômica ou politicamente -, busca estender e intensificar os efeitos do poder o máximo possível e, ao mesmo tempo, tenciona ampliar a docilidade e a utilidade de todos os indivíduos submetidos ao sistema (Foucault 2001b: 179-180).

Quanto aos dispositivos disciplinares, ou instrumentos do poder disciplinar, também são em número de três os seus principais, quais sejam: o olhar hierárquico, a sanção normalizadora e o exame. Vejamos brevemente cada um deles. O olhar hierárquico consiste antes na idéia mais ampla de vigilância. A vigilância é a mais importante máquina, a principal engrenagem do poder disciplinar: ela contribui para automatizar e desindividualizar o poder, ao passo que contribui para individualizar os sujeitos a ele submetidos. Ao mesmo tempo, a vigilância produz efeitos homogêneos de poder, generaliza a disciplina, expandindo-a para além das instituições fechadas. Nesse sentido, pode-se dizer que ela assegura, como explica Foucault, uma distribuição infinitesimal do poder.

Quais são, portanto, essas novas mecânicas de poder que a vigilância traz consigo? A mais importante delas é, sem dúvida, aquilo que Foucault considera ser uma espécie de 'ovo de colombo' da política: o panóptico de Bentham. Essa espécie de utopia política da arquitetura tem o condão de

fazer com que a vigilância seja permanente em seus efeitos, mesmo se é descontínua em sua ação; que a perfeição do poder tenda a tornar inútil a atualidade de seu exercício; que esse aparelho arquitetural seja uma máquina de criar e sustentar uma relação de poder independente daquele que o exerce; enfim, que os detentos se encontrem presos numa situação de poder de que eles mesmos são portadores (Foucault 2001b: 166).

Ao ser adotada a arquitetura circular nas prisões e escolas, nos hospitais e fábricas, enfim, em toda sorte de instituições que tenham a marca da disciplina, o poder converteu-se em algo invisível e inverificável. Para que o dispositivo disciplinar exerça-se plenamente em todos os seus 
efeitos basta que aqueles que estão a ele submetidos saibam que são vigiados ou, mais (ou menos) do que isso, que são potencialmente vigiados. A potencialidade da vigilância, sua possibilidade apenas, é por si suficiente para que o poder disciplinar se exerça justamente porque com ela uma sujeição real nasce de uma relação fictícia. Esse caráter ficcional, por assim dizer, decorre do fato de que, ao saberem-se sujeitos a um único olhar a tudo pode ver permanentemente, os indivíduos disciplinam-se a si mesmos, e o fazem constantemente em simetria à permanência desse olhar onipresente. Na medida em que a visibilidade constante dos indivíduos e a invisibilidade permanente do poder disciplinar fazem com que os indivíduos se adestrem, se ajustem e se corrijam inicialmente por moto próprio, pode-se afirmar que a vigilância substitui a violência e a força. Sem essas, passa a ser ainda possível se falar em um adestramento ou readestramento espiritual, das almas, e não dos corpos.

Com a vigilância, o poder disciplinar torna-se um sistema integrado, converte-se no conceito de diagrama. ${ }^{9}$ Não há um centro, não há um chefe no topo da forma piramidal desse poder: a engrenagem como um todo produz poder. Trata-se de um poder em essência relacional. Daí Foucault afirmar que o poder disciplinar funciona como uma máquina, se organiza como uma pirâmide e opera como uma rede. Com sua forma hierarquizada, contínua e funcional, a vigilância também estabelece uma simetria crescente entre poder e produção, poder e saber. Mais uma vez, a fórmula foucaultiana se repete: quanto mais poder se exercer sobre os indivíduos, maior será a sua produtividade; quanto mais o poder discipliná-los, mais saber eles gerarão.

O segundo dos principais dispositivos disciplinares é a sanção normalizadora. No núcleo de cada sistema disciplinar funciona um pequeno mecanismo penal. A disciplina traz consigo uma maneira específica de punir. O castigo disciplinar tem a função de reduzir os desvios, ele é corretivo. Com a sanção, os indivíduos são diferenciados em função de sua natureza, de suas virtualidades, de seu nível ou valor... eles são, enfim, avaliados, e por isso são, por mais uma vez e por mais um motivo, individualizados. A punição característica do poder disciplinar, contudo, não visa nem a expiação, nem a repressão: "a penalidade perpétua que atravessa todos os pontos e controla todos os instantes das instituições disciplinares

${ }^{9}$ Sobre a noção de dispositivo, em geral, e as noções de diagrama e programa, em particular, veja-se, respectivamente, Deleuze: 1989 e Deleuze: 1996. 
compara, diferencia, hierarquiza, homogeneíza, exclui. Em uma palavra, ela normaliza" (Foucault 2001b: 153). Com o poder disciplinar surge, portanto, o poder da norma, que substitui - de forma muito diferenciada, é claro - o papel que a lei desempenhava no regime do poder da soberania. Saiu de cena a codificação dos comportamentos para entrar em cena a normalização das condutas. ${ }^{10}$

Finalmente, o exame é o último dos dispositivos do poder disciplinar que nos resta comentar. Antes de mais nada, cabe ressaltar que ele consiste em uma espécie de articulação entre a vigilância e a sanção normalizadora. Em outras palavras, o exame constitui o indivíduo como objeto para análise e posterior comparação. Trata-se de um controle normalizante, uma vigilância que permite qualificar, classificar e punir. O exame estabelece sobre os indivíduos uma visibilidade através da qual eles são diferenciados e sancionados. Disso decorre que o exame é o resultado do somatório entre objetivação e sujeição: "ele manifesta a sujeição dos que são percebidos como objetos e a objetivação dos que se sujeitam" (Foucault 2001b: 154). Objetivação essa, ressalte-se, que opera pela concomitância entre a visibilidade dos sujeitos e a invisibilidade da disciplina. Ritualizado ao extremo, o exame tem ainda, e mais uma vez no sistema foucaultiano, o atributo de colocar em funcionamento relações de poder que permitem obter saber. Mais do que isso, com o exame, o indivíduo passa a ser, ao mesmo tempo, efeito e objeto do poder $e$ do saber: "o exame não se contenta em sancionar um aprendizado; é um de seus fatores permanentes" (Foucault 2001b: 155).

A vigilância do pan-óptico, a disciplina e o exame: todos os dispositivos disciplinares funcionam, portanto, como um laboratório de poder, proporcionando um aumento de saber em todas as suas frentes. Durante a segunda metade do século XVIII, no entanto, essas tecnologias disciplinares do poder passam a ser acrescidas, integradas por outras e novas técnicas de poder que não possuem em sua essência, contudo, a idéia de disciplina. Antes de passarmos a analisar essa nova tecnologia de poder que é o biopoder, o Quadro 1, abaixo, nos apresenta uma espécie de contraposição entre as modalidades soberana e disciplinar do poder, comentadas acima.

${ }^{10}$ Sobre o assunto veja-se Ewald: 1989. 


\section{Quadro 1: Poder Soberano e Poder Disciplinar}

\begin{tabular}{|c|c|}
\hline Poder Soberano & Poder Disciplinar \\
\hline indivíduo-sociedade & indivíduo-corpo \\
\hline terra e seus produtos & corpo \\
\hline $\begin{array}{c}\text { apropriação e expiação } \\
\text { de bens e riquezas }\end{array}$ & $\begin{array}{l}\text { anatomia política do } \\
\text { corpo humano }\end{array}$ \\
\hline existência física do soberano & disciplina \\
\hline tributação & vigilância \\
\hline produção de bens e riquezas & maximização da força \\
\hline monarquia & sociedade disciplinar \\
\hline lei & norma \\
\hline codificação & normalização \\
\hline Estado & $\begin{array}{l}\text { instituições: escolas, } \\
\text { oficinas, hospitais etc. }\end{array}$ \\
\hline Direito & Ciências Humanas \\
\hline continuidade & descontinuidade \\
\hline contrato & disciplina \\
\hline $\begin{array}{l}\text { visibilidade do soberano e } \\
\text { invisibilidade dos súditos }\end{array}$ & $\begin{array}{l}\text { invisibilidade da disciplina e } \\
\text { visibilidade dos sujeitos }\end{array}$ \\
\hline
\end{tabular}

O poder disciplinar, portanto, passa, a partir da segunda metade do século XVIII, a ser complementado pelo biopoder. Complementado porque não se opera efetivamente uma substituição, mas apenas uma pequena modificação - ou adaptação -, e jamais uma exclusão. Em outras palavras, o biopoder implanta-se de certo modo no poder disciplinar, ele embute e integra em si a disciplina, transformando-a ao seu modo. $\mathrm{O}$ biopoder "não suprime a técnica disciplinar simplesmente porque é de outro nível, está noutra escala, tem outra superfície de suporte e é auxiliada por instrumentos totalmente diferentes" (Foucault 1999: 289). Ambas as espécies de poder passam assim, portanto, a coexistir no mesmo tempo e no mesmo espaço.

São muitas as variações, entretanto, encontradas entre as duas mecânicas de poder em questão. Ao passo que o poder disciplinar se faz sentir nos corpos dos indivíduos, o biopoder aplica-se em suas vidas. Enquanto a disciplina promove a individualização dos homens, o biopoder acarreta uma massificação, tendo em vista que ele se dirige não aos 
indivíduos isolados, mas à população. Daí que os efeitos do biopoder se fazem sentir sempre em processos de conjunto, coletivos, globais... processos esses que fazem parte da vida, da vida de uma população: os nascimentos, as doenças e as mortes constituem exemplos desses processos. E o biopoder trata exatamente do conjunto desses processos de natalidade, longevidade e mortalidade, seja comparando a proporção dos nascimentos e dos óbitos, seja verificando a taxa de fecundidade de uma população. Enfim, são vários os exemplos cedidos por Foucault para explicar essa modalidade de poder.

O que é importante perceber é que em todos esses processos nos quais se exerce o biopoder há concomitantemente uma extensa produção de saber. Entram em campo as ciências exatas e biológicas: a Estatística e a Biologia, principalmente, passam a ser extremamente importantes nesse momento em que se necessitam de demografias, políticas de natalidade, soluções para endemias, entre outras coisas mais. A questão da higiene pública passa a ser a principal pauta da Medicina e, com ela, podemos pensar que o biopoder assume uma certa forma de poder de polícia, tal como entendemos essa última modalidade de poder contemporaneamente. $\mathrm{O}$ biopoder traz ainda consigo novos mecanismos e novas instituições, tais como a poupança e a seguridade social (Foucault 1999: 290-291).

É, portanto, a cidade e a população que entram em cena no regime do biopoder. E isso é relevante, segundo Foucault, porque nem o poder da soberania, nem o poder disciplinar operavam com essas noções. A cidade e a população passam a ser problemas políticos, problemas da esfera do poder. E esses problemas ou fenômenos também apresentam outras características em si peculiares. Eles são, por exemplo, essencialmente problemas coletivos, de massa, cuja ocorrência se dá sempre em série e nunca de forma isolada ou individualizada. $\mathrm{O}$ biopoder não intervém no indivíduo, no seu corpo, como faz o poder disciplinar; ao contrário, intervém exatamente naqueles fenômenos coletivos que podem atingir a população e afetá-la - disso decorre que precisa estar constantemente medindo, prevendo, calculando tais fenômenos e, para isso, o biopoder cria alguns mecanismos reguladores que o permitam realizar tais tarefas como, por exemplo, aumentar a natalidade e a longevidade, reduzir a mortalidade e assim por diante.

Os mecanismos de previdência - ou prevenção -, criados com o biopoder, sinalizam uma preocupação com a otimização da vida e não, perceba-se, uma maximização de forças que a disciplina do poder disciplinar tenta por si assegurar. Com efeito, a disciplina, no âmbito do biopoder, 
é convertida em regulamentação. Regulamenta-se para assegurar e garantir a vida, para prevenir e evitar a morte. Essa regulamentação, ressalte-se, não é exclusiva do Estado. Foucault menciona uma série de focos do biopoder que se localizam no âmbito infra e paraestatal. É o caso, por exemplo, de algumas instituições médicas, das caixas de auxílio e dos seguros (Foucault 1999: 293-299).

Poder disciplinar e biopoder, afinal, sobrepõem-se e superpõem-se constante e incessantemente. O melhor exemplo que Foucault fornece dessa espécie de acoplagem entre as duas modalidades de poder é dado pelo tema da sexualidade. De acordo com Foucault, a sexualidade se tornou um campo de importância estratégica no século XIX justamente porque dependia, simultaneamente, de processos disciplinares e biológicos, individualizantes e massificantes, controladores e regulamentadores... enfim, a sexualidade se situa exatamente entre os corpos dos indivíduos singulares e a unidade múltipla da população. No campo do saber produzido em conjunto pela fusão entre as mecânicas disciplinares e biopolíticas do poder, Foucault nos dá o exemplo da Medicina como um tipo de poder-saber que incide concomitantemente sobre os corpos individuais e sobre a população. A Medicina, portanto, assim como a sexualidade, possui tanto efeitos disciplinares como efeitos regulamentadores (Foucault 1999: 300-302).

Há portanto um elemento em comum que transita entre o poder disciplinar e o biopoder, entre a disciplina e a regulamentação, e que possibilita a manutenção do equilíbrio entre a ordem disciplinar do corpo e a ordem aleatória da população. Esse elemento é a norma, "que pode tanto se aplicar a um corpo que se quer disciplinar quanto a uma população que se quer regulamentar" (Foucault 1999: 302). A norma da disciplina e a norma da regulamentação dão origem ao que Foucault chama de sociedade de normalização, uma sociedade regida por essa norma ambivalente, na qual coexistem indivíduo e população, corpo e vida, individualização e massificação, disciplina e regulamentação.

Dizer que o poder, no século XIX, tomou posse da vida, dizer pelo menos que o poder, no século XIX, incumbiu-se da vida, é dizer que ele conseguiu cobrir toda a superfície que se estende do orgânico ao biológico, do corpo à população, mediante o jogo duplo das tecnologias de disciplina, de uma parte, e das tecnologias de regulamentação, de outra (Foucault 1999: 302). 
O Quadro 2, abaixo, apresenta uma justaposição entre os elementos e as características do poder disciplinar e do biopoder.

\section{Quadro 2: Poder Disciplinar e Biopoder ${ }^{11}$}

\begin{tabular}{|c|c|}
\hline Poder Disciplinar & Biopoder \\
\hline indivíduo-corpo & população \\
\hline corpo & vida \\
\hline $\begin{array}{c}\text { anatomia política do } \\
\text { corpo humano }\end{array}$ & biopolítica da espécie \\
humana
\end{tabular}

\section{CONSIDERAÇÕES FINAIS}

É preciso ter cuidado para não confundir os conceitos que Foucault teceu para compreender historicamente o poder tal como ele se manifestou ao longo dos séculos (estamos falando, evidentemente, do poder disciplinar e do biopoder) e o significado do conceito de poder, este apenas em forma abstrata, que criou para lograr opor-se às teorias tradi-

11 Observe que no Quadro 1, a primeira coluna (poder da soberania) encontra-se em contraposição com a segunda (poder disciplinar); no Quadro 2, a primeira coluna (poder disciplinar) e a segunda (biopoder) não se encontram em uma relação de oposição entre si. 
cionais do poder e, assim, promover a limpeza de terreno necessária para colocar em prática a sua analítica - ou genealogia - do poder. O poder disciplinar e o biopoder, portanto, assim como o poder da soberania, operam como categorias historicamente constituídas, ou melhor, são chaves de análise e interpretação do poder tal como ele se manifestou através de seus efeitos na história da sociedade ocidental. Enquanto categorias analíticas, descritivas, contudo, o poder disciplinar e o biopoder servem como instrumentos para que Foucault crie ainda uma nova categoria; na verdade, um novo conteúdo, um novo significado para o conceito de poder.

Pode-se pensar, por conseguinte, que, com Foucault, o conceito de poder passa a ganhar um sentido emancipatório, libertador, ao liberar-se do estigma, do falso estigma, da repressão. Ao emancipar-se desse falso atributo e passar a conter em si mesmo o ideal de emancipação, o poder, agora visto como algo positivo, irrompe também como pura e plena produtividade. O poder produz: ele constrói; destrói e reconstrói; ele transforma, acrescenta, diminui, modifica a cada momento e em cada lugar a si mesmo e a cada coisa com a qual se relacione em uma rede múltipla, móvel, dinâmica, infinita... o poder é produção em ato, é a imanência da produtividade. Acima de tudo, como vimos, o poder está em estreita relação com o saber. Poder e saber se produzem e auto-reproduzem, estabelecem uma relação de mútua dependência - e de mútua independência produzindo, dessa fusão interprodutiva, um novo conceito: o poder-saber.

Quando compreendemos o conceito foucaultiano de poder dessa forma, ou melhor, quando conseguimos o enxergar além da analítica e do olhar historiográfico de seu autor, ele parece ser algo bem distante daquilo que a história do pensamento político - e jurídico também, por que não? sempre definiu como poder. Esse novo conceito de poder parece se assemelhar com um outro cunhado no século XVII na contramão da intensa produção teórica-política que, naquela época, consolidou definitivamente o significado jurídico-repressivo do poder que Foucault tanto quis rejeitar e evitar. Estamos falando do conceito de potência, criado por Spinoza na contracorrente do movimento contratualista que assolou seu século e fez entrar, definitivamente, para a História o significado do poder enquanto soberania, lei, repressão.

Na última fase de sua obra, hoje freqüentemente denominada de "hermenêutica do sujeito", Foucault parece ainda acrescer ao seu conceito de poder um certo caráter autopoiético, no sentido de um autogoverno, um cuidado de si que autocapacita e, em última instância, também emancipa. Esses últimos desdobramentos adquiridos pelo conceito foucaultiano de 
poder em suas obras finais - especialmente em algumas entrevistas e textos esparsos e nos dois últimos volumes da História da sexualidade - parecem torná-lo ainda mais próximo do conceito de potência de Spinoza. Mas essa análise, bem como uma investigação acerca das possíveis relações entre esses dois conceitos, não poderá ser feita aqui e terá de se constituir tema de um outro trabalho futuro, no qual o conceito de poder foucaultiano seja analisado não mais sob o prisma genealógico como fizemos aqui, mas sim sob o novo ângulo que marca a segunda e derradeira fase de sua obra.

THAMY POGREBINSCHI é doutoranda em Ciência Política no Iuperj.

\section{REFERÊNCIAS BIBLIOGRÁFICAS}

ASSOCIATION POUR LE CENTRE MICHEL FOUCAULT. 1989. Michel Foucault philosophe. Rencontre internationale Paris 9, 10, 11 janvier 1988. Paris: Éditions de Seuil.

BURKE, Peter (ed.). 1992. Critical Essays on Michel Foucault. Cambridge: Scolar Press.

COUSINS M. e HUSSAIN A. 1984. Michel Foucault. London: Macmillan.

DELEUZE, Gilles. 1986. Foucault. Paris: Minuit.

1989. "Qu'est-ce qu'un dispositif?” in Michel Foucault philosophe. Rencontre internationale Paris 9, 10, 11 janvier 1988. Paris: Éditions de Seuil.

1996. "Desejo e Prazer" in Peter Pál Pelbart e Suely Rolnik (org.), Cadernos de Subjetividade, Núcleo de Estudos e Pesquisas da Subjetividade do Programa de Estudos Pós-Graduados em Psicologia Clínica da PUC-SP, num. especial, São Paulo, jun. 1996, p. 13 a 25.

EWALD, François. 1989. "Um pouvoir sans dehors" in Michel Foucault philosophe. Rencontre internationale Paris 9, 10, 11 janvier 1988. Paris: Éditions de Seuil.

LEMERT C. e GILLAN G. 1982. Michel Foucault: Social Theory and Transgression. New York: Columbia University Press.

FONTANA, Alessandro e BERTANI, Mauro. 1999. "Situação do Curso" in Em Defesa da Sociedade. São Paulo: Editora Martins Fontes.

FOUCAULT, Michel. 1979. Microfísica do poder. Rio de Janeiro: Graal. 1995a. "O Sujeito e o Poder" in RABINOW, Paul e DREYFUS, Hubert. 1995. Michel Foucault. Uma trajetória filosófica. Para além do estruturalismo e da hermenêutica. Rio de Janeiro: Forense Universitária.

1995b. "Entrevista a Hubert L. Dreyfus e Paul Rabinow". in RABINOW, Paul e DREYFUS, Hubert. 1995. Michel Foucault. Uma Trajetória Filosófica. Para além do estruturalismo e da hermenêutica. Rio de Janeiro: Forense Universitária. 1996. A Verdade e as formas jurídicas.Rio de Janeiro: Nau Editora.

1997. Resumo dos cursos do Collège de France. Rio de Janeiro: Jorge Zahar Editor.

1999. Em defesa da sociedade. São Paulo: Editora Martins Fontes.

2000. Essential Works, Volume 3: Power. Editado por James D. Faubion. London: Penguin Books.

2001a. História da sexualidade,Volume 1: A Vontade de saber. Rio de Janeiro: Graal. 
2001b. Vigiar e punir. Petrópolis: Editora Vozes.

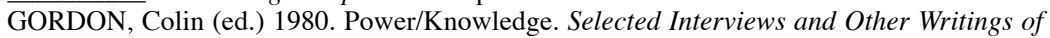
Michel Foucault. New York: Pantheon Books.

2000. "Introduction" in Michel Foucault Essential Works, Volume 3: Power. Editado por James D. Faubion. London: Penguin Books.

HABERMAS, Jürgen. 1986. "Taking Aim at the Heart of the Present" in Foucault: A Critical Reader. Editado por David Couzens Hoy. Oxford: Blackwell 2002. O Discurso filosófico da modernidade. São Paulo: Editora Martins Fontes.

HOY, David Couzens. 1986. Foucault: A Critical Reader. Oxford: Blackwell.

JONES, Colin e PORTER, Roy. 1994. Reassessing Foucault: Power, medicine and the body. London: Routledge.

KRITZMAN, Lawrence (ed.). 1988. Michel Foucault: Politics, Philosophy and Culture. New York: Routledge.

MACHADO, Roberto. 1979. "Introdução: Por uma Genealogia do Poder" in Microfísica do poder. Rio de Janeiro: Graal.

MACHEREY, Pierre. 1989. "Pour une histoire naturelle des normes" in Michel Foucault philosophe. Rencontre internationale Paris 9, 10, 11 janvier 1988. Paris: Éditions de Seuil.

MOSS, Jeremy (ed.). 1998. The Later Foucault. London: Sage Publications.

RABINOW, Paul e DREYFUS, Hubert. 1995. Michel Foucault. Uma trajetória filosófica. Para além do estruturalismo e da hermenêutica. Rio de Janeiro: Forense Universitária.

SIMONS, Jon. 1995. Foucault and the Political. London: Routledge. 